\title{
Comparison of performance in physiology subject assessed by short essay type questions and multiple choice questions of first year medical students
}

\author{
Pradeep Kumar' ${ }^{1}$, P Ghildiyal' ${ }^{2}$, Ravindra Singh Rajpoot ${ }^{3}$, Sanjeev Kumar ${ }^{4}$ \\ ${ }^{1}$ Professor, Department of Physiology, King Georges Medical University, Lucknow, ${ }^{2}$ Professor, Department of Surgery, \\ Hind Institute of Medical Sciences Ataria, Sitapur, ${ }^{3}$ Associate Professor, Department of Physiology, Uttar Pradesh \\ University of Medical Sciences, Saifai, Etawah, ${ }^{4}$ Senior Resident, Department of Medicine, Government Medical \\ College, Jalaun (Orai), UP, India
}

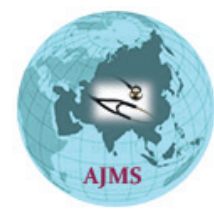

A B S T R A C T

Background: Assessment and evaluation in the curriculum of medical education plays an important role to enhance the learning ability of medical students and should provide the level of actual performance as well as the capacity to improve overall performance. Aims and Objectives: In the present study, the performance of medical students in Physiology was assessed by conventional type short essay questions (SEQ) and multiple choice questions (MCQ). Materials and Methods: This prospective (observational) study was conducted in the subject of Physiology, A total of 380 samples were taken from students enrolled for the $1 \mathrm{st}$ year medical curriculum in year 2013 to 2015 . The subjects were divided in two groups: subjects of this group-I was assessed with two theory papers consist of short essay question (SEQ), practical exam without OSPE. The subjects of group-II were assessed their theory part only by MCQs and maximum part of practical exam by objective structured practical examination (OSPE). Results: The theory performance was significantly higher $(p<0.05)$ in group-II students assessed by totally MCQ based two system tests and one terminal exams as compared to conventional type (SEQ). While the marks obtained in practical was assesses by six lab leaving tests, one terminal practical exam (OSPE) was also significantly high $(p<0.005)$ as compared to group-l. Our data showed that the performance of two problem solving tests (one long clinical case) and grant viva (oral) was significantly less in group-II (Table 1). Conclusion: The objectivity of questions prefers over short essay questions by students as they scores well in theory as well as in practical exams, while they poorly performed in clinical exam (the assessment of higher cognitive functions). The objectivity may eliminate the subjective difference in conventional type of evaluation.

Key words: Physiology assessment SEQ multiple choice questions, OSPE, Medical Students
http://nepjol.info/index.php/AJMS DOI: 10.3126/ajms.v8i1.15977 E-ISSN: 2091-0576 P-ISSN: 2467-9100

\section{INTRODUCTION}

Physiology is one of the important subjects of basic medical sciences for the medical curriculum and is taught in the first year of medical course, along with anatomy and biochemistry. In most of the medical colleges and universities of India, the physiology subject is taught by means of didactic lectures, demonstrations, tutorials, and practical classes including human, hematology and animal experiments. ${ }^{1}$ Assessment and evaluation of learner is decisive steps in curriculum of medical education and it plays an important role to enhance the learning ability of medical students and should provide the level of actual performance as well as the capacity to improve overall performance. ${ }^{2}$ While adopting an assessment method, it must be kept in mind that what should be assessed and utmost care should be taken to rule out the questions whether the adopted method is valid, reliable and feasible. 
In the developed countries like United States, the assessment of medical students is largely based on the model uses six interrelated domains of competence: communication and interpersonal relation, medical knowledge, patient care, professionalism, practice-based learning and improvement, and systems-based practice. ${ }^{3}$ Over the past few years, the authorities of medical colleges in India initiated new efforts to provide accurate, reliable, and timely assessments of the undergraduates and post graduate students. ${ }^{4}$

The conventional type of assessment and evaluation of medical subjects usually leads to stress and fear. Due to apprehension of failure and less marks in the subject, students may indulge in malpractice to secure good marks. ${ }^{5}$ With best of my knowledge, this is the first report elucidating the effect of total MCQ type assessment (theory examination) on the performance of medical students in subject of physiology.

\section{MATERIALS AND METHODS}

This prospective (observational) study was conducted in the subject of Physiology, A total of 380 samples were taken out of 500 students enrolled for the $1^{\text {st }}$ year medical curriculum in year 2013 and 2015. The evaluator and the students were blinded for the study. The subjects were divided in two groups : Group-I ( $\mathrm{n}=170)$, subjects of this group were assessed with two theory paper consist of short essay question, short notes and some diagram/ flow chart making questions and practical exam without OSPE. The subjects of group-II $(n=210)$ were assessed their theory part only by MCQs and maximum part of practical exam by objective structured practical examination (OSPE). The inclusion criteria for group-I and II were that: the student must be enrolled for study of Physiology subjects and regularly received didactic lectures with teaching aids $6 \mathrm{hrs} \mathrm{a}$ week and tutorials/ seminars $2 \mathrm{hrs}$ a week. They should also attend practical sessions including demonstration of $6 \mathrm{hrs}$ a week. The study consisted of comparison of two types of assessment/ evaluation that are the non- structured (conventional type (Group-I)) and structured (MCQs and OSPE Group-II). In the MCQs, four options were given for a question and the single best answer was to be marked on OMR sheet. Two MCQ papers consisted of 200 questions of 50 marks in each paper were given to solve one MCQ paper in three hours and there was no negative marking. The practical exam of group included OSPE (4 OSPE in three labs). The two theory paper consisting of SEQ and short notes (50 marks and three hours in each paper) on the same system were given to group -II. Every effort was made to avoid unethical act of students during examination and to eliminate examiners bias when the theory paper was evaluated by the faculty.

\section{RESULTS}

A total of 380 students of MBBS were included in the study. It showed that that the average age (in years) of students in group-I and group-II was 21.42 2.05 and $22.02 \pm 1.40$ respectively without any significant difference. The difference in gender was also not significant between two groups. The students of both the groups were composed of different socioeconomic and pattern of schooling (state board, CBSE and ISC board). The students of both the groups were exposed to same type of theory and practical teaching by the same faculty. The theory performance (marks obtained in \%) of group-I students was $45.25 \% \pm 10.34$ in two system tests (SEQ based) and one terminal exam 48.26\% \pm 8.4 (SEQ and short notes). While in the practical the marks obtained in percent were $56.66 \% \pm 9.58$ in six lab leaving tests (one long and one short practical) and it was $54.26 \% \pm 7.25$ in one terminal practical exam (non OSPE). Percent of marks obtained in two problem solving tests was $58.44 \% \pm 6.22$ (one long clinical case) and in grant viva (oral) was $55.82 \% \pm 2.24$ (Table 1). The theory performance was significantly higher $(\mathrm{p}<0.05)$ in group-II students assessed by totally MCQ based two system tests and one terminal exam. While the marks obtained in practical was assesses by six lab leaving tests (OSPE), one terminal practical exam (OSPE) was also significantly high $(\mathrm{p}<0.005)$. Our data showed that the performance of two problem solving tests (one long clinical case) and grant viva (oral) was significantly less in group-II (Table 1). Student's feedback showed that they prefer objective type of exams (Table 2).

\section{DISCUSSION}

Assessment of competency of medical students without subjective and methodological biasness is a troublesome task

\section{Table 1: Performance of students in two type of assessment}

\begin{tabular}{lcc} 
Mode of assessment & Group-I Marks obtained in \% & Group-II Marks obtained in \% \\
\hline System tests (theory) & $45.25 \pm 10.34$ & $55.35 \pm 8.33$ \\
Terminal exam (theory) & $48.26 \pm 8.40$ & $58.46 \pm 6.42$ \\
Lab (practical exam) & $56.66 \pm 9.58$ & $64.84 \pm 11.3$ \\
Terminal practical exam & $54.26 \pm 7.25$ & $62.44 \pm 7.52$ \\
PBL (clinical exam) & $58.44 \pm 6.22$ & $48.24 \pm 7.28$ \\
Oral (viva) & $55.82 \pm 2.24$ & 45.005 \\
\hline
\end{tabular}




\begin{tabular}{lcc} 
Table 2: Feedback by students & \\
\hline & Group-I & Group-II \\
\hline Preference of MCQs and OSPE & $76 . \%$ & $89 \%$ \\
Preference of SEQ & $69 \%$ & $72 \%$ \\
Combined MCQs and SEQ & $28 \%$ & $23 \%$ \\
Preference of MCQ book & $45 \%$ & $100 \%$ \\
Change in teaching pattern for MCQs & $84 \%$ & $87 \%$ \\
\hline
\end{tabular}

of the learning process in many medical institutions of India. ${ }^{6}$ Various methods including multiple choice question (MCQs), short essay questions (SEQs), LAQ-long answer questions and combination of these were tested to assess the medical students. ${ }^{7,8}$ Nowadays, MCQs type of assessment method is taking edge over other methods due to their reliability, validity, and ease of scoring. In present study, we analyses the effectiveness of MCQs and OSPE type of assessment in first year medical curriculum. ${ }^{9}$ Our data showed that objective type of examinations results in to greater scoring over conventional type of method in theory and practical. In previous studies ${ }^{10,11}$ authors observed that the score obtained in MCQs was similar to the score of SEQs and concluded that the students who performed well in the essay were also likely to do well in the MCQs. In contrast, the observations of our study are strengthened by a study ${ }^{12}$ in which it was stated that MCQs scores higher compared with long essay questions. Our data showed that students exposed to MCQs and OSPE poorly performed in clinical (PBL) and oral (viva) exams. It may be due to attention of students diverted from text books towards made easy and MCQ books, as observed in feedback given by students. On the basis of our data, along with other authors ${ }^{11,13,14}$ we also believe that long essay questions and clinical problem based assessment is a sensitive test that evaluates higher cognitive skill including analysis, interpretation and application of skills. Item writing flows ${ }^{15}$ were observed in $46 \%$ of MCQs given to medical students in the United States of America resulting in 15\% extra failure that were otherwise pass. The objectivity in assessment patterns is useful to evaluate large strength of students in short time and eliminate subjective difference in SEQ evaluation amongst different examiners in conventional exams.

\section{CONCLUSION}

The objectivity of questions prefers over short essay questions by students as they scores well in theory as well as in practical exams, while they poorly performed in clinical exam (the assessment of higher cognitive functions). The objectivity may eliminate the subjective difference in conventional type of evaluation. Therefore it can be said that there should be a supervised guidelines on preparing questions of higher cognitive level for medical students to assess the learning outcomes.

\section{REFERENCES}

1. Ghosh S. Combination of didactic lectures and case-oriented problem-solving tutorials toward better learning: perceptions of students from a conventional medical curriculum. Adv Physiol. Educ. 2007; 31: 193-197.

2. Fraser SW and Greenhalgh T. Coping with complexity: educating for capability. BMJ 2001; 323:799-803.

3. Batalden P, Leach D, Swing S, Dreyfus H and Dreyfus S. General competencies and accreditation in graduate medical education. Health Aff (Millwood) 2002; 21(5): 103-111.

4. Gopalakrishnan S and Udayshankar PM. Question Vetting: The Process to Ensure Quality in Assessment of Medical Students. Journal of Clinical and Diagnostic Research : JCDR 2014; 8(9):XM01-XM03.

5. Epstain RM. Assessment in medical education. N. Engl. J Med 2007; 356:387-396.

6. Badyal DK, Desai C, Tripathi SK, Dhaneria SP, Chandy SJ and Bezbaruah BK. Postgraduate pharmacology curriculum in medical institutions in India: Time for need-based appraisal and modifications. Indian Journal of Pharmacology 2014; 46(6):584-589.

7. Surapaneni KM and Tekian A. Concept mapping enhances learning of biochemistry. Med Educ Online 2013; 18: 10.3402.

8. Harden RM and Gleeson FA. Assessment of clinical competence using on objective structured clinical examination (OSCE). Med Educ1979; 13: 41-54.

9. Siddiqui NI, Bhavsar VH, Bhavsar AV and Bose S. Contemplation on marking scheme for Type $X$ multiple choice questions, and an illustration of a practically applicable scheme. Indian $\mathrm{J}$ Pharmacol 2016; 48:114-121.

10. Pepple DJ, Young LE and Carroll RG. A comparison of student performance in multiple-choice and long essay questions in the MBBS stage I physiology examination at the University of the West Indies (Mona Campus). Adv Physiol Educ 2010; 34: 86-89.

11. Moqattash S, Harris PF, Gumaa KA and AbuHijleh MF. Assessment of basic medical sciences in an integrated systemsbased curriculum. Clin Anat 1995; 8:139-147.

12. Momin MA, Pardeshi ML and Ghongane BB. "Comparative assessment of multiple choice questions versus short essay questions in pharmacology examinations." Indian journal of medical sciences 2010; 64. (3): 118.

13. Oyebola DD, Adewoye OE, Iyaniwura JO, Alada AR, Fasanmade AA and Raji YA. Comparative study of students performance in physiology assessed by multiple choice and short essay questions. Afr J Med Sci 2000; 29: 201-205.

14. Cees W, Vleuten V, John S and Roger J. Assessment of clinical competence. The Lancet 2001; 357:945-949.

15. Rodríguez-Díez MC, Alegre M, Díez N, Arbea $L$ and Ferrer $M$. Technical flaws in multiple-choice questions in the access exam to medical specialties in Spain. BMC Medical Education 2016; 16:47.

\footnotetext{
Authors Contribution:

Authors Contribution:
PK - Concept and design of the study, reviewed the literature; JPG - Manuscript preparation and critical revision of the manuscript; RSR - Data collection, literature search, statistically analyzed and interpreted and given the final draft of manuscript; SK - Helped in preparing first draft of manuscript edited the manuscript, critical revision of the manuscript.
}

Source of Support: Nil, Conflict of Interest: None declared. 